\title{
Students' Attitudes as Regard to Distance Learning of Anatomy Courses throughout COVID-19 Pandemic Lockdown Period among Medicine and Paramedical Faculties of Najran University, Saudi Arabia
}

\author{
Khlood Mohammed Mehdar \\ Faculty of Anatomy, College of Medicine, Najran University, Najran, Kingdom of Saudi Arabia
}

Received August 29, 2020; Revised September 29, 2020; Accepted November 1, 2020

\begin{abstract}
Cite This Paper in the following Citation Styles
(a): [1] Khlood Mohammed Mehdar, "Students' Attitudes as Regard to Distance Learning of Anatomy Courses throughout COVID-19 Pandemic Lockdown Period among Medicine and Paramedical Faculties of Najran University, Saudi Arabia," Universal Journal of Educational Research, Vol. 8, No. 11B, pp. 6166 - 6172, 2020. DOI: 10.13189/ujer.2020.082253.
\end{abstract}

(b): Khlood Mohammed Mehdar (2020). Students' Attitudes as Regard to Distance Learning of Anatomy Courses throughout COVID-19 Pandemic Lockdown Period among Medicine and Paramedical Faculties of Najran University, Saudi Arabia. Universal Journal of Educational Research, 8(11B), 6166 - 6172. DOI: 10.13189/ujer.2020.082253.

Copyright $\bigcirc 2020$ by authors, all rights reserved. Authors agree that this article remains permanently open access under the terms of the Creative Commons Attribution License 4.0 International License

\begin{abstract}
Globally, the consequences of the COVID-19 pandemic have influenced learning systems in all types of educational institutions. During the lockdown instituted to prevent viral transmission in Saudi Arabia, it was decided to utilize digital platforms as an alternative mode of delivery of educational material. The transition to e-learning has many challenges. Anatomy is a foundation science which traditionally necessitates practical teaching

learning platforms could offer both pedagogues and students benefits and potential difficulties. A significant proportion of scholars reported that e-learning offered an opportunity of self-motivated and self-sufficient learning experiences, and that interaction with educators and peers was facilitated. Also, it was generally felt that digital visual components were not an adequate replacement for the dissection laboratory.
\end{abstract} sessions in the dissection laboratory for effective information delivery. Transferring to an e-learning format was not straightforward for either the educators or students. The aims of this study was to find out medical and paramedical trainees' perspectives in relation to receiving an anatomy teaching programme in an e-learning environment during the lockdown period necessitated by the coronavirus outbreak. Medical and paramedical students at Najran University who participated in digital anatomy programmes during lockdown were surveyed through use of an online questionnaire. Quantitative cross sectional analysis was performed. The results showed that scholars rapidly became proficient in using online tools. Approximately half of the students were sufficiently self-disciplined to interact successfully with the digital system. Forty percent stated that they would be willing to continue using online resources going forwards. Digital
Keywords Anatomy, Distance Learning, COVID-19, Pandemic, Medical, Blackboard

\section{Introduction}

In Saudi Arabia (SA) and worldwide, the COVID-19 pandemic has necessitated changes in the way education is delivered across schools and universities. Since pedagogues are now opting to work from their home environment, they are having to make use of digital platforms to support their teaching [1]. In the initial stages of the COVID-19 pandemic when the majority of nations were severely impacted by the virus and entered lockdown, the Ministry of Education in SA incorporated measures in 
order to limit potential transmission of the virus amongst university students. These policies encompassed several recommendations. In the first instance, students have been permitted to study at home and engage in remote learning opportunities. A dedicated television channel was launched to act as a modality for lesson delivery for all educational age-groups. An e-learning platform was set up specifically to support university education which is now available to both lecturers and scholars at all universities. A second initiative has been taken to place priority on enabling students to receive the tuition required to finish their current level of study. Finally, a range of assessment and appraisal formats have been developed to substantiate the other e-learning opportunities and to ensure that they reduce onus on the learners.

\subsection{Coronavirus Pandemic: Reshaping Education}

The extent of global interrelations and networks has been revealed by the coronavirus pandemic; no one is untouched by the crisis. Borders are no barrier to either desirable or undesirable events, all of which merge worldwide. Within this wider setting, scholastic environments have become less inclined to describe a teacher as someone who shares their expertise with their students. The latter are now in a position to retrieve the necessary knowledge simply by tapping their phone, computer or tablet screens. This would indicate that pedagogues now need to establish a new direction in teaching, which encourages their mentees to add to society in a productive manner [1]. The health crisis has mandated redesigning modes of educational provision to include distance learning (DL), thus allowing varied and less rigid approaches. Teachers now need to acquire a diverse range of proficiencies in order to procure their scholars' commitment, e.g. interactive skills, ideas for teamwork, encouragement, understanding and sensitivity [2].

DL is a valuable educational resource; information can be presented to students at a specific time or situation [3]. It is an overarching method that can embrace teaching in the absence of lecture theatres [1]. Remote education has been established for some time and comprises a range of learning options. These encompass: postal courses where information exchange occurs via traditional mail and with minimal contact between student and teacher; tele courses where educational material is presented on radio or television channels; publication of educational CD-ROMs, which offer one-way computerised learning environs; internet-delivered modules, which can be engaged with in a synchronous or asynchronous time frame; and device-based modalities, e.g. cellular phones, personal digital assistance platforms, and audio devices, such as iPods or MP3 players [4]. The abilities of students to utilize remote learning opportunities is influenced by a range of issues, e.g. external factors relating to the educational establishment such as processing or direction problems, and internal or student-related issues such as desire to learn and skill-base. Additional influences relate to the student's family circumstances and academic parameters including the course outline or mode of provision [5]. Universities throughout SA have employed the online Blackboard (Blackboard Inc, 2000) (BB) software, which facilitates the usage of the virtual classroom.

\subsection{What is the Blackboard?}

BB software is one of the most commonly utilized platforms to enable blended learning; not only is it being employed in universities in SA, but across the world. BB provided an educational experience within virtual surroundings, together with a course administration package. This web-based programme comprises features and a framework that can be tailored to requirements and can be applied to small or much more widespread teaching situations, seamlessly merging with existing student knowledge bases and verification schemes. It provides a means with which to add digitally-based facets to series that are typically taught in person; alternatively, it can be utilized to create lessons that are solely delivered online [6]. The software company claim that the use of BB's online components and organizational elements augments students' study experience [7]. In addition, it facilitates contact and exchange between fellow students and offers the options of discussion via boards, e-correspondence and chat rooms [7]. Learners are therefore able to use these interactive modalities to exchange their thoughts and activities with their classroom fellows and their educators. Pedagogues are able to modify and customize their resources according to their student's needs; interactive graphics, audio and video presentations, animation effects, and PowerPoint options are available. Continuous 24-hour access to $\mathrm{BB}$ is provided, making educational material available to students at their leisure [7]; [8].

Traditional higher educational establishments offer remote learning as a matter of routine. Lecture-based theoretical programmes that can easily utilize DL include Islamic culture, language courses, managerial and education options. However, some courses require practical sessions typically performed in a laboratory setting, e.g. chemistry, anatomy, and physiology, amongst others [9]. The lockdown brought about by the coronavirus pandemic limited physical access to these areas, which has meant that pedagogues and students have had to resort to electronic learning modalities for both the theoretical and hands-on course content. Najran University is an institution which is using $\mathrm{BB}$ for teaching in several subjects through the university website.

Over the last few months, the e-learning lecturer has created concentrated learning programmes in this digital discipline to facilitate the varying departments and students in using this digital platform. Medical and paramedical faculties now need to teach their syllabus online, which 
incorporates traditionally laboratory-based subjects, e.g. anatomy. This is a challenging subject to transfer to the e-learning environment. The aim of this study therefore was to investigate the feasibility of anatomy teaching modules at universities without access to laboratory facilities during lockdown. Further objectives included assessing students' engagement with course resources, satisfaction, and the challenges faced.

\section{Aims}

The aims of this study were to determine the need for flexibility, learning interactions and difficulties encountered in relation to students studying anatomy as part of medical and paramedical training during the lockdown period at Najran University.

\section{Methods}

\subsection{Study Design and Setting}

A cross-sectional quantitative study was performed using designed questionnaire which conducted as an online survey. Inclusion criteria comprised scholars who were receiving anatomy tuition through the digital platform as part of medical or paramedical courses at Najran University throughout lockdown who had undertaken at least one related appraisal. The questions were classified into five categories, incorporating questions regarding the virtual nature of the course, students' interface with the educational material, interaction with other course personnel and comprehension of the course content and their overall contentment with the anatomy teaching programme. No private individual data were collected. Likert's scale was utilized offering a 5 point response, i.e. strongly agree, agree, neither agree nor disagree, disagree and strongly disagree. The questionnaire took approximately 5 minutes to complete. One open-ended question was added to give students an opportunity to add a freely worded observation regarding DL.

\subsection{Data Analysis}

The survey was performed over the two-month period of June and July 2020 at the conclusion of the summer term. Data were imported into Excel software for analysis. The proportions of the varying answers for each question were computed; the results were expressed in diversion charts.

\subsection{Instruments}

The questionnaire was developed by the researcher. Google forms were used to circulate it to all participants that met the inclusion criteria.

\subsection{Participants of the Study}

In order to ensure that the participants reflected the total population, students enrolled to the study were members of the medical and paramedical faculties from Najran University, SA. 70 students completed the questionnaire.

\section{Results}

\section{The response rate of the students was about}

The answers to the first section of the questionnaire, which asked about users' proficiency, are depicted in Figure $1.54 \%$ of students strongly agreed that they had quickly acquired the skills to utilise the digital environment successfully. At the third part, about fifty percent expressed that they were proficient in computer use and that they were comfortable working online. However, approximately one fifth felt uncomfortable working in the e-learning setting.

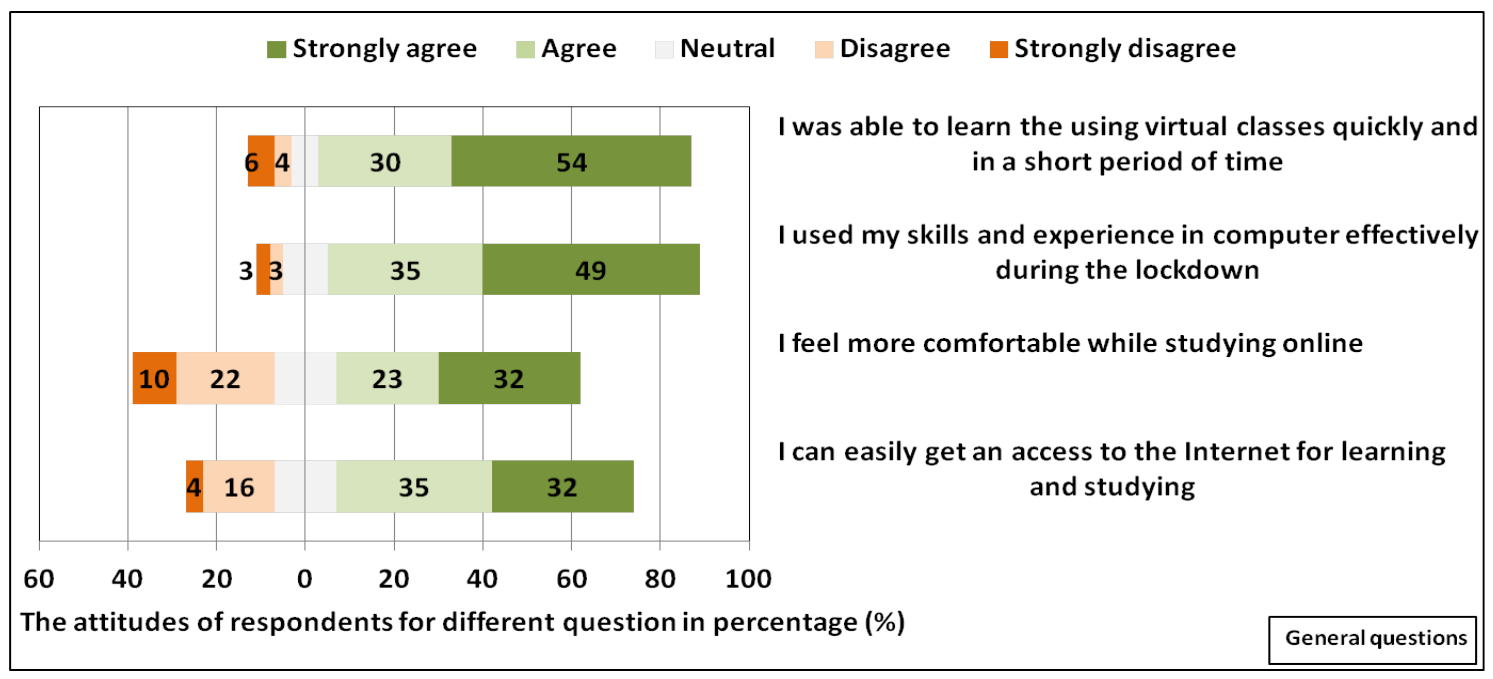

Figure 1. Responses to section 1: General questions regarding online study (\% students). 


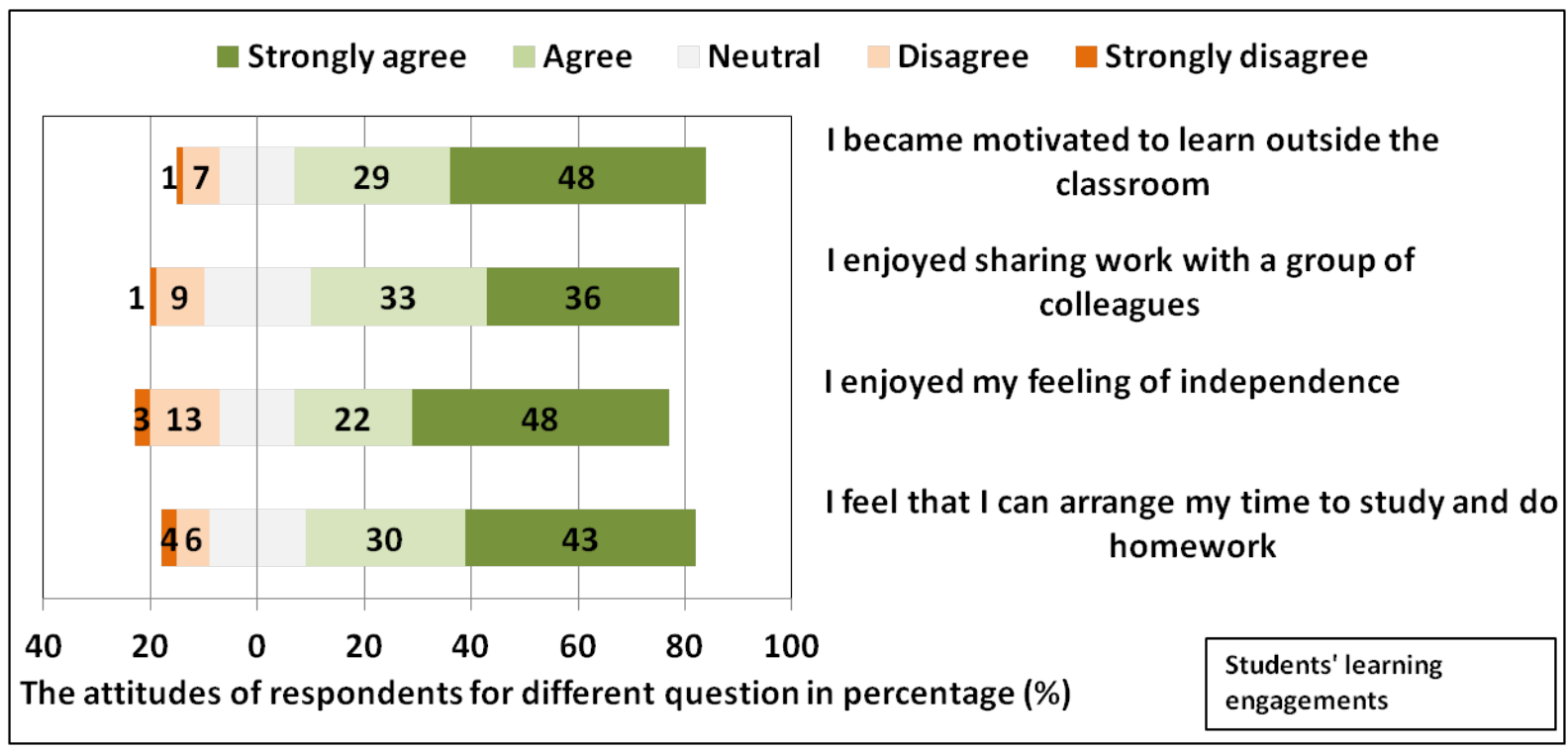

Figure 2. Responses to section 2: Study engagement with virtual classes (\% students).

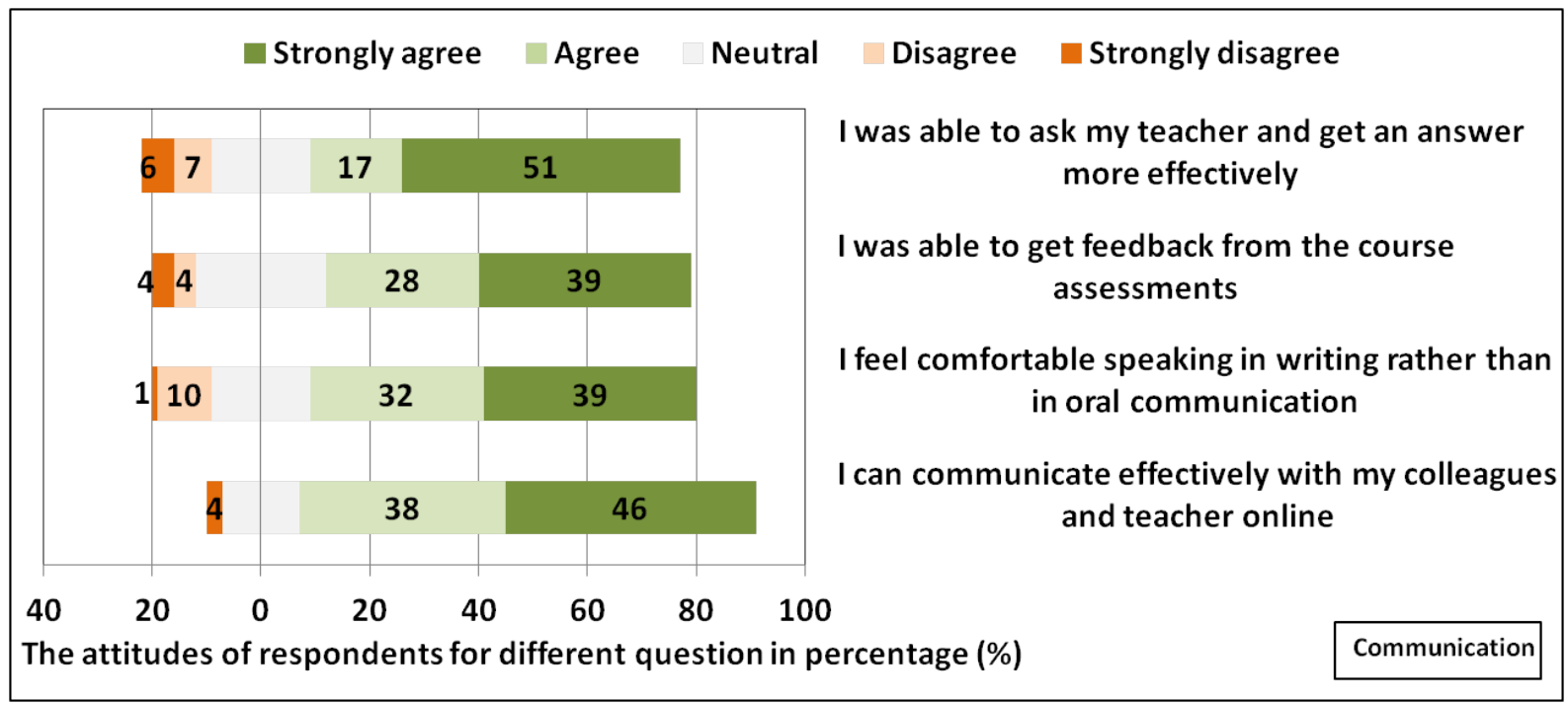

Figure 3. Responses to section 3: Effectiveness of communication using DL (\% students).

Question 2 assessed the ability of the students to interact with the digital platform (Figure 2). $48 \%$ of the population answered 'strongly agree' when asked if they had incentive to work away from the physical teaching environment. Just below than $40 \%$ took pleasure in engaging with their fellow students; only $1 \%$ reported the converse. Nearly half of the cohort were positive about taking personal responsibility for their study, and $43 \%$ felt strongly that they could organize their study and assignment time effectively.

The data presented in Figure 3 illustrates the answers to the questionnaire section relating to students' ability to interact in the virtual classroom. Approximately 50\% strongly agreed that they could question their educators and receive a response effectively; an additional $17 \%$ graded their response to this query 'agree'. Nearly $40 \%$ students felt that they obtained feedback from course appraisals through the DL environment; only $4 \%$ felt that this was not the case. An equivalent number strongly agreed that they were relaxed using written dialogue; a further $32 \%$ opted for the 'agree response' to this question stem. 


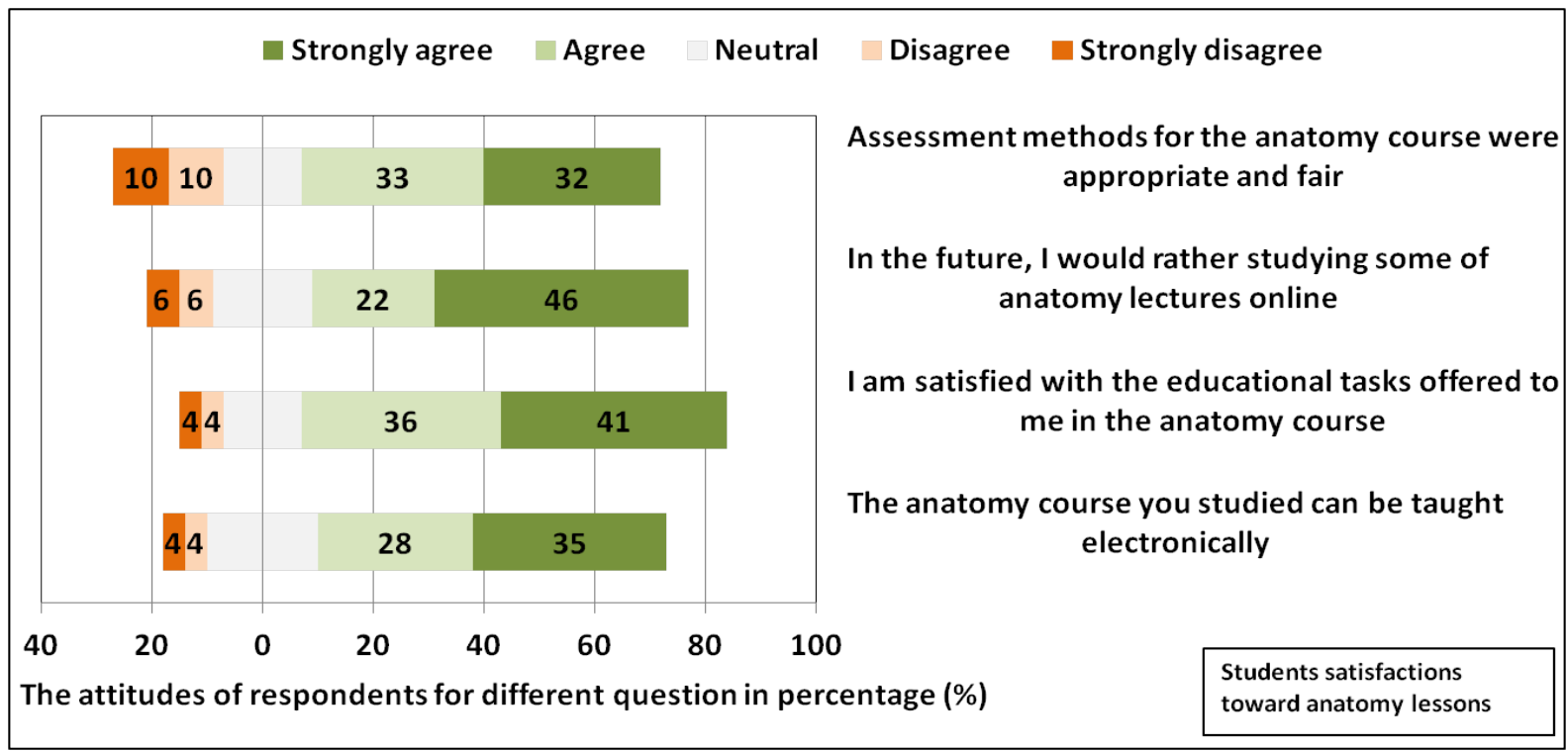

Figure 4. Responses to section 4: Content with online anatomy course material and appraisal methods (\% students).

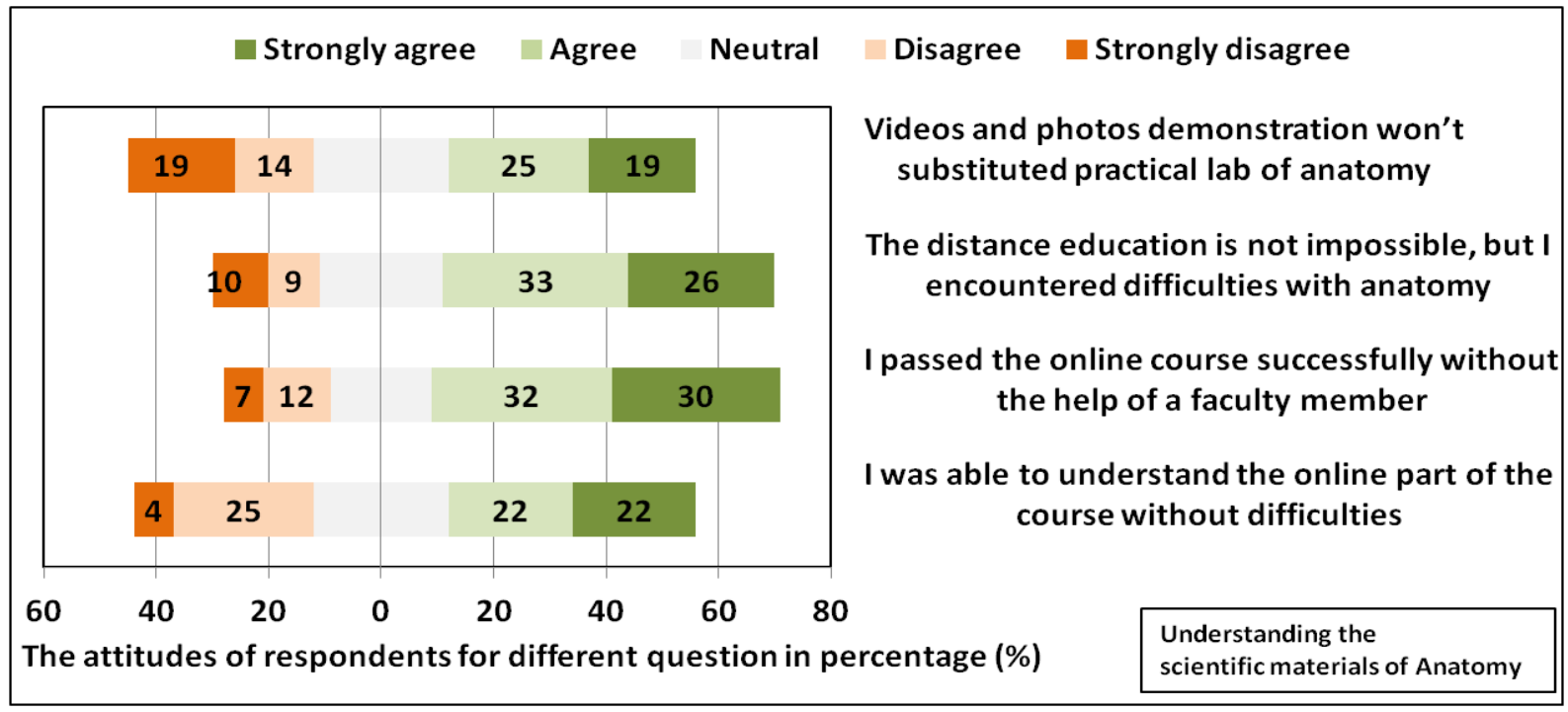

Figure 5. Responses to section 5: Students' comprehension of online academic resources for anatomy course (\% students).

Anatomy is potentially the most challenging foundation sciences subject in the faculties of medicine and applied medicine. As a consequence, the questions in this survey covered student's satisfaction with the remote version of the anatomy programme offered during lockdown (Figure $4)$. It was revealed that $35 \%$ were in strong agreement and $38 \%$ were in agreement, of the scholars thought that this subject was able to be presented successfully online, with nearly half stating that they would prefer DL for some of the lectured course content going forward. About $6 \%$ strongly disagreed with the latter statement. $41 \%$ and $36 \%$ expressed strong agreement or agreement, respectively, with the fact that they were content with the study assignments that they had been given; the equivalent numbers for those views relating to the course appraisal system were $32 \%$ and $33 \%$, respectively.
Figure 5 illustrates how the students perceived their comprehension of the academic content of the anatomy course. Students were polarized on their views regarding whether the online image modalities, i.e. still images and video presentations could replace the laboratory practical sessions of the course. $19 \%$ strongly agreed that the online modalities were adequate whereas $19 \%$ disagreed. Difficulties in understanding the online anatomy material were found in one fifth of the students; a tenth of those surveyed encountered no challenges.

\section{Discussion}

Traditionally, a physical environment for university education has always been deemed essential. However, the 
circumstances of the COVID-19 pandemic lockdown meant that neither educators nor their scholars could physically enter university buildings, thus the conventional classroom became unavailable. Educational institutions were forced to transfer teaching activities to a digital platform [1]. The concept of pedagogy has therefore been transformed by the coronavirus crisis. Conventional education has required educators in lecture halls and classrooms to communicate in such a manner as to encourage student involvement and to facilitate students to express their ideas and contribute to the overall process. Thus, the coronavirus pandemic has required a change in education delivery from offline to online. This was the case in this study; as during the semester the study transited from traditional delivery method to be via online platform. Each institution has merged a diverse range of materials to establishing an educational system to offer home study and to facilitate successful remote learning. All the universities within SA have offered students the use of BB for this purpose.

E-learning was not an entirely novel concept; technological advancement has already led to the implementation of e-universities which offer students a virtual classroom via the internet. The success rate of students using such online systems has been documented to be equivalent to those studying in traditional offline learning environments. The demographic traits of students had no influence on this outcome data; all students appeared content with the electronic educational experience [10]. This finding supported our study as more than $50 \%$ of the participants were able to adopted easily in using online system, although they were not used it before. One study evaluated the results of an appraisal performed for a macroeconomics course within two groups of students, i.e. those who had chosen to study online and those that participated in the conventional teaching arena. After the data were corrected for sample selection bias, the e-learning group scored 4 points higher than the second group [11].

Some students have found difficulties in participating in DL, requiring more direction and advice [12]. In contrast, one survey documented that students studying remotely were highly content with the course materials and the teachers. A caveat to this opinion, however, was that they did not communicate with the teachers influenced their perspective [13]. Opposite to this finding, in this study more than half of participants found that they can communicate effectively via online lessons. In order for students to have a positive outcome from DL, they need to be able to work alone and also to display incentive to study [14], the latter particularly being a potential impediment to remote education. Scholars that were less self-sufficient and lacked purpose struggled more with DL than their peers [15]. Kirtman (2009) observed that those students was able to self-motivate and effectively organize their time were able to utilize digital resources at their own rate [16].
The results of the questionnaire in this research revealed that approximately $50 \%$ of the students were confident and self-motivated towards remote learning.

Given the tendency of this modality to appear impersonal, it is necessary to providing both students and their lecturers' means so they can communicate effectively and created conducive environment for learning. In the questionnaire responses, students described the communication between the two parties as being more efficacious, and also indicated that they preferred the critique on their appraisal through this modality. Hiltz and Wellman (1997) suggested that the onus is on the instructors to facilitate interaction within the digital materials and to attempt to simulate the environs of a live lecture hall [17]. The benefits of routine pupil-teacher contact on student's accomplishments have been described by Robinson (1995) [18].

For those scholars planning a career in medical or paramedical settings, anatomy is an essential foundation subject. Laboratory sessions have always been considered a vital component of such courses in order to facilitate the appreciation of three-dimensional anatomical structures [19]. However, the consequences of the pandemic have required both students and teachers to reframe their approach to this subject and adjust to the novel system of DL.

Conventional lectures and laboratory practical have been substituted by videos, still imagery and audio materials. During this project, the success of these online resources and students' engagement with them have been assessed. Despite a minority of scholars expressing 'strongly disagree' to the concept of anatomy being taught on the digital platform, most were not only content with online teaching in the context of the lockdown, but also stated an interest in continuing to use e-learning materials in the future. Students did however report that the online visual aids did not fully replace the hands-on practical experience of the laboratory. This observation is contrary to a previously published study that has suggested that dissection practicals are old fashion learning strategy and that mobile applications were a more efficient mode of teaching [20]. Controversy still exists regarding the ability of videos to provide the same calibre of education. Several studies have suggested that use of video material improves examination results; on the other hand, it has also been reported that they have no effect or may even be associated with poorer assessment outcomes [21]. Scholars themselves, however, appear to prefer the video format of teaching. One study, performed in Ireland, revealed that over three quarters of the students in their sample had made use of digital sources and in particular YouTube to gain access to video clips relating to anatomical study [22].

\section{Conclusions}

Many advantages and challenges have been faced by 
students and tutors because of online courses. Students found that studying online gave them independency, motivation and eased the communication. Regarding anatomy course, although students were satisfied by the tasks they been given and the assessment methods, they reported that videos, images would not substitute the practical session.

\section{Study Limitations}

The limitation faced in this study was the small sample size, this occurs due to the number of the students who were accepted by university. Also, the University located in remote area (southern region at the border with Yemen) that was the reason for lowering the number of applicants especially in the medical specialities.

\section{REFERENCES}

[1] H. Yulia, "Online Learning to Prevent the Spread of Pandemic Corona Virus in Indonesia," ETERNAL (English Teach Journal), vol. 11, no. 1, 2020.

[2] P. Luthra and S. Mackenzie, "ways COVID-19 could change how we educate future generations," in World Economic Forum, 4AD, 2020.

[3] S. Haghighi and M. D. Tous, "Attitudes towards student support system in distance learning: a questionnaire survey," Styles Commun, vol. 6, no. 1, 2014.

[4] L. K. Grant and M. Courtoreille, "Comparison of fixed-item and response-sensitive versions of an online tutorial," Psychol Rec, vol. 57, no. 2, pp. 265-272, 2007.

[5] L. A. Gonzalez, Factors Affecting Student Success in Distance Learning Courses at a Local California Community College: Joint Governance Perspectives. University of California, Santa Barbara, 2012.

[6] H. A. Z. H. El Zawaidy, "Using Blackboard in online learning at Saudi universities: faculty member's perceptions and existing obstacles," Int Interdiscip J Educ, vol. 1, no. 1457, pp. 1-9, 2014.

[7] A. Chawdhry, K. Paullet, and D. Benjamin, "Assessing Blackboard: Improving online instructional delivery," Inf Syst Educ J, vol. 9, no. 4, p. 20, 2011.

[8] M. Masino, "Integration of Blackboard in the Online Learning Environment.," J Instr Pedagog, vol. 16, 2015.
[9] T. K. Shih et al., "A survey of distance education challenges and technologies," Int J Distance Educ Technol, vol. 1, no. 1, pp. 1-20, 2003.

[10] P. Navarro and J. Shoemaker, "Performance and perceptions of distance learners in cyberspace," Am J Distance Educ, vol. 14, no. 2, pp. 15-35, 2000.

[11] O. R. Harmon and J. Lambrinos, "Online format vs. live mode of instruction: Do human capital differences or differences in returns to human capital explain the differences in outcomes?," 2006.

[12] P. B. T. Blieszner Rosemary, "Promises and pitfalls of the interactive television approach to teaching adult development and aging," Educ Gerontol, vol. 25, no. 8, pp. 741-753, 1999.

[13] E. Inman, M. Kerwin, and L. Mayes, "Instructor and student attitudes toward distance learning," Community Coll J Res Pract, vol. 23, no. 6, pp. 581-591, 1999.

[14] B. Gilbert, S. John, and F. College, "Online Learning Revealing the Benefits and Challenges How has open access to Fisher Digital Publications benefited you ?," 2015.

[15] W. C. Savenye, "Improving online courses: What is interaction and why use it?," Distance Learn, vol. 2, no. 6, p. $22,2005$.

[16] L. Kirtman, "Online versus in-class courses: An examination of differences in learning outcomes.," Issues Teach Educ, vol. 18, no. 2, pp. 103-116, 2009.

[17] S. R. Hiltz and B. Wellman, "Asynchronous learning networks as a virtual classroom," Commun ACM, vol. 40, no. 9, pp. 44-49, 1997.

[18] B. Robinson, "Learner support," Open distance Learn today, vol. 221, 1995.

[19] S. C. Marks Jr, "The role of three-dimensional information in health care and medical education: The implications for anatomy and dissection," Clin Anat Off J Am Assoc Clin Anat Br Assoc Clin Anat, vol. 13, no. 6, pp. 448-452, 2000.

[20] P. Alexandra, H. Gineta, M. Aida, and J. George, "Applications of mobile devices in anatomy studies," vol. XVII, pp. 359-363, 2018.

[21] D. L. Choi-Lundberg, W . A. Cuellar, and A. M. W illiams, "Online dissection audio-visual resources for human anatomy: Undergraduate medical students' usage and learning outcomes," Anat Sci Educ, vol. 9, no. 6, pp. 545-554, 2016.

[22] D. S. Barry, F. Marzouk, K. Chulak-Oglu, D. Bennett, P. Tierney, and G. W. O'Keeffe, "Anatomy education for the YouTube generation," Anat Sci Educ, vol. 9, no. 1, pp. 90-96, 2016. 